\title{
Exogenous bacterial DnaK increases protein kinases activity in human cancer cell lines
}

\author{
Francesca Benedetti ${ }^{1}$, Sabrina Curreli ${ }^{2}$, Robert C. Gallo ${ }^{2}$ and Davide Zella ${ }^{{ }^{*}} \mathbb{C}$
}

\begin{abstract}
Background: Studies of molecular mechanisms underlying tumor cell signaling highlighted a critical role for kinases in carcinogenesis and cancer progression. To this regard, protein kinases regulates a number of critical cellular pathways by adding phosphate groups to specific substrates. For this reason, their involvement in the complex interactions between the human microbiota and cancer cells to determine therapy and tumor progression outcome is becoming increasingly relevant. Mycoplasmas are components of the normal human microbiota, and several species have also been associated to human diseases, including certain cancers. It is also important to note that Mycoplasmas and their proteins are a component of the common tumor microenvironment. In addition, several epidemiological, in vivo and in vitro studies indicate a close involvement of Mycoplasmas in cellular transformation and cancer progression.

Methods: In this study, we investigate the effect of exogenous Mycoplasma DnaK on kinases activity by treating in vitro four different eukaryotic cancer cell lines, namely lung and prostate cancer, colon adenocarcinoma, and neuroblastoma. Phosphorylation of kinases and specific substrates was measured at 20 and 60 min.

Results: Kinome analysis of our data indicates that Mycoplasma DnaK promotes the dysregulation of the activity of specific kinases and their substrates, with a known involvement in carcinogenesis and cancer progression.

Conclusions: Given the similarity in structure and amino acid composition of this protein with other bacterial DnaKs we provide a novel mechanism whereby components of the human microbiota and present in the tumor microenvironment are able to deregulate phosphorylation events occurring during carcinogenesis and cancer progression.
\end{abstract}

Keywords: Mycoplasma, DnaK, Kinase, Phosphorylation, Cancer

\section{Background}

Protein kinases are key regulators of several cellular functions and by adding phosphate groups they can modify the activity of a protein, increase or decrease enzyme activity, direct the localization of many proteins, alter other biological activities such as transcription and translation. Moreover, some phosphorylation sites on a given protein are stimulatory while others are inhibitory

\footnotetext{
*Correspondence: dzella@ihv.umaryland.edu

${ }^{1}$ Institute of Human Virology and Global Virus Network Center,

Department of Biochemistry and Molecular Biology, University

of Maryland School of Medicine, Baltimore, MD 21201, USA

Full list of author information is available at the end of the article
}

[1]. The human genome encodes more than 500 protein kinases that transfer a $\gamma$-phosphate group from ATP to serine, threonine, or tyrosine residues $[2,3]$. There are seven major groups of protein kinases, AGC (containing PKA, PKG, PKC families) [4], CAMK (Calcium/calmodulin-dependent protein kinase) [5], CK1 (Casein kinase 1) [6], CMGC (containing CDK, MAPK, GSK3, CLK families) [7], STE (Homologs of yeast Sterile 7, Sterile 11, Sterile 20 kinases) [8], TKL (Tyrosine kinase-like) [9], TK (Tyrosine kinase) [10] that can be further subdivided into families and sub-families based on sequence similarity and biochemical function [9]. A further eighth atypical kinases group assembles all the kinases that have no sequence similarity to typical kinases, but are known or

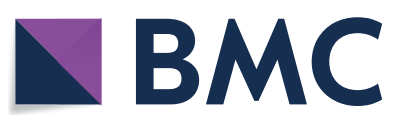

(c) The Author(s) 2021. This article is licensed under a Creative Commons Attribution 4.0 International License, which permits use, sharing, adaptation, distribution and reproduction in any medium or format, as long as you give appropriate credit to the original author(s) and the source, provide a link to the Creative Commons licence, and indicate if changes were made. The images or other third party material in this article are included in the article's Creative Commons licence, unless indicated otherwise in a credit line to the material. If material is not included in the article's Creative Commons licence and your intended use is not permitted by statutory regulation or exceeds the permitted use, you will need to obtain permission directly from the copyright holder. To view a copy of this licence, visit http://creativeco mmons.org/licenses/by/4.0/. The Creative Commons Public Domain Dedication waiver (http://creativecommons.org/publicdomain/ zero/1.0/) applies to the data made available in this article, unless otherwise stated in a credit line to the data. 
predicted to have enzymatic activity, and a similar structural fold to typical kinases [11].

Recent advances in the understanding of the molecular mechanisms underlying tumor cell signaling have elucidated a critical role for kinases in carcinogenesis, from cellular transformation to promotion of metastasis [12]. Most protein kinases are involved in the processes of cell proliferation, survival and migration, and their dysregulation or overexpression mostly leads to hyperphosphorylation of the target substrates. This dysregulation is implicated in several steps of cancer initiation and progression, as well as cancer recurrence [13-18]. Deregulation of kinase function may lead also to immunological, neurological and metabolic diseases [19]. Recently, several small-molecule kinase inhibitors have been developed for the treatment of diverse types of cancer where kinases hyperactivation is implicated in tumor progression, and many of these molecules have proven to be successfully in clinical therapy $[12,20]$. Despite progress in tumor treatments, heterogenous cell population survive leading to tumor resistance. So far, the responsible mechanisms are only partially understood and they include pro-angiogenic signaling pathways activation [21] and multidrug resistance and antiapoptotic proteins upregulation [22-24]. However, most of the molecular mechanisms responsible for tumor dedifferentiation, aggressiveness and relapse related to kinases activation remain to be discovered.

Mycoplasmas are the smallest and simplest self-replicating bacteria belonging to the family of Mollicutes. They are part of the normal human microbiota, but several species have been associated to human diseases, like acute respiratory illness, genitourinary tract infections, joint infections and neurologic disorders [25-30]. They have also been associated with certain cancers, though the correlation is still unclear. However, several epidemiological [31], in vivo and in vitro studies indicate a close involvement of Mycoplasmas in cellular transformation and cancer progression [32-41].

Our group has previously demonstrated that a mycoplasmal protein, notably a chaperone protein belonging to the Heath shock protein (Hsp)-70 family, DnaK, binds Poly-(ADP-ribose) Polymerase (PARP)-1, a protein that plays a critical role in the pathways involved in DNA damage and repair by reducing its catalytic activity. It also binds USP10, a key p53 regulator, reducing p53 stability and its anti-cancer functions. We also observed tumorigenesis in vivo when Severe Combined Immune Deficient (SCID) mice were injected with Mycoplasma, and based on these results we proposed that Mycoplasma DnaK may have oncogenic activity through the inhibition of DNA repair and p53 functions [39, 40]. In addition, it has been recognized that DnaK belongs to a class of bacterial proteins that is also expressed on the surface of bacteria and secreted [42-45]. By interacting with receptors on the surface of cellular membranes and triggering their responses, these proteins exert a different function with respect to their original one and likely primary function. This "multitasking" capacity is called "protein moonlighting" and is becoming increasingly important to our understanding of mechanisms of bacterial pathogenicity associated with bacteria $[46,47]$.

In this study, we further investigate the ability of extracellular Mycoplasma DnaK to upregulate the activity of cellular kinases. We treated with a recombinant DnaK in vitro four different cell lines, representative of lung, prostate, colon adenocarcinoma, and neuroblastoma. We then analyzed the protein phosphorylation of kinases and their specific substrates at 20 and $60 \mathrm{~min}$. Kinome analysis of our data indicates a selective dysregulation of the activity of certain kinases and their substrates involved in carcinogenesis and cancer progression. Our data indicate that Mycoplasma DnaK activates certain kinases known to be involved in different steps of tumorigenesis. Since some other bacterial DnaKs are similar in structure and amino acid composition, we provide a novel mechanism whereby components of the human microbiota are able to modify the activity of protein kinases implicated in carcinogenesis and cancer progression.

\section{Materials and methods}

\section{Cell lines}

A human colorectal carcinoma cell line (HCT116), an adenocarcinomic human alveolar basal epithelial cells (A549), a human prostate cancer cell line (PC-3), and a human neuroblastoma cell line (SH-SY5Y) used in the experiments were all from ATCC. The cells were cultured in a humidified incubator at $37{ }^{\circ} \mathrm{C}$ in $5 \% \mathrm{CO}_{2}$ in McCoy medium (HCT116), F-12 K medium (A549 and PC-3), and F12+EMEM (1:1) medium (SH-SY5Y), all containing $10 \%$ fetal bovine serum (FBS), $100 \mathrm{U} / \mathrm{ml}$ penicillin and $100 \mathrm{U} / \mathrm{ml}$ streptomycin. SH-SY5Y were also differentiated in neuron-like cells by adding Retinoic Acid (RA) $(10 \mu \mathrm{M})$ to the culture for 7 days [48]. Briefly, cells were seed in T25 (or T75) flasks at a concentration of about $10^{6}$ cells $/ \mathrm{ml}$, maintained in an incubator at $37^{\circ} \mathrm{C}$, $5 \% \mathrm{CO}_{2}$, and RA was added at the beginning of the differentiation process. The medium was replaced every 2-3 days, with concomitant addition of RA. During this period of time the cells were observed under direct light microscope to verify the progress toward differentiation into an elongated neuronal-like phenotype, as evidenced by a decreased amount in cell body clumping, and extension of numerous thin, branched neuritic processes that often connect to neighboring cells. The differentiated 
cells were finally used to analyze the effect of DnaK on kinases activation as described below.

\section{Expression and purification of Mycoplasma fermentans MF-I1 DnaK}

Recombinant DnaK-V5 was obtained as previously described [39]. Briefly, MF-I1 DnaK sequence was inserted into a cloning vector, followed by the transformation and expression of the protein, subculture into TB/ LB with Kanamycin, and subsequently fractionated and purified (Biomatik USA, Wilmington, DE). After purification, the protein was extensively dialyzed against PBS $1 \mathrm{X}, \mathrm{pH}$ 7.4. Coomassie blue-stained SDS-PAGE (> 85\%) was used to determine purity. Aliquots of the protein were kept at $-80^{\circ} \mathrm{C}$ after reconstitution. Particular care was taken to avoid frequent freeze-thaws.

\section{Human phospho-kinase antibody array}

Cells were treated with the recombinant DnaK-V5 protein $(10 \mu \mathrm{g} / \mathrm{ml})$ for 20 and $60 \mathrm{~min}$, then harvested and lysed using the Lysis Buffer 6 from the Proteome Profiler Human Phospho-Kinase Array Kit (ARY003B, R\&D Systems, Inc. USA \& Canada). The amount of extracted proteins was measured using the Bradford assay (Bio-Rad). The Proteome Profiler Human Phospho-Kinase Array Kit was used to detect the relative levels of protein phosphorylation according to the manufacturer's instruction. The signal produced is proportional to the amount of phosphorylation in the bound analyte. The spot signals were quantified using ImageJ software and normalized to the internal reference spots first and then to the corresponding not treated samples.

\section{Data analysis}

A signal increase of $30 \%$ above the negative control (corresponding to 3 times the common 10\% standard error in the assay) was considered a relevant effect in our analysis. In addition, activation of kinases between 20 and 30\% was considered as a potential deregulation. KinMap, a web-based tool, allowed us to determine the association score (built in the application) of the activated kinases with cancer [49].

\section{Data visualization (Circos plots)}

Circular visualization (Circos plot) of the overlapping phosphorylated kinases and substrates in the different cancer cell lines was performed using the software package for visualizing data and information, according to the distributor's instructions (http://circos.ca/).

\section{Results}

Deregulation of kinases activation is an established hallmark of cancer initiation and progression and several kinases and their downstream pathways have recently become important targets for the treatment of several cancers [50]. In order to verify if purified and exogenously added Mycoplasma DnaK has a role in kinases activation triggered by membrane cellular receptors, we treated different cancer cells lines in vitro with the Mycoplasma fermentans DnaK. Cells were harvested at early time points following stimulation $(20$ and $50 \mathrm{~min}$ ). We reasoned that this short time points were appropriate to observe both early transduction signals and more immediate downstream events involving typical target substrates for phosphorylation pathways. For this analysis we used an assay where antibodies specific for a number of phosphorylates proteins are deposited on a membrane. Following stimulation with DnaK for the indicated period, the cell lysates are incubated with the membrane and processed following the manufacturer's instructions. By binding the phosphorylated protein to the specific antibody, each spot allows for detection, quantification and direct comparison of the amount of phosphorylated proteins, including both kinases and the most relevant target substrates. The latter were important indicators of the downstream events triggered by the kinase activation.

We detected a different kinase response among the cell lines analyzed, in that one of them responded very poorly (A549), one was stimulated to a very high degree (SH-SY5Y), while HCT116 and PC-3 fell somewhere in between (compare Figs. 1, 2, 3, 4).

\section{Effect of DnaK on A549 lung adenocarcinoma cell line}

More in detail, we note that only one kinase, namely p38, was stimulated in A549 cell line at $20 \mathrm{~min}$ and its activation increased at a longer time point, about $1 \mathrm{~h}$, while no substrates were phosphorylated above our threshold level. Slightly below our threshold level, one additional kinase was activated (FAK) and p53 was phosphorylated in position S46 (Fig. 1 and Table 1). Phosphorylation of p53 at Ser46 upregulates the ability of p53 to induce apoptosis [51].

\section{Effect of DnaK on HCT116 colorectal carcinoma cell line} In the HCT116 cell line, exogenous DnaK stimulated multiple phosphorylation events involving several kinases belonging to the TK family (namely FAK, Hck, Lyn and Lck) and the RSK1/2/3 group (of the AGC family) increased their phosphorylation status by more than $30 \%$, between 20 and 50 min of treatment. A number of other kinases were also activated just slightly below the threshold (namely p38a, MSK1/2, Akt1/2/3, WNK1 


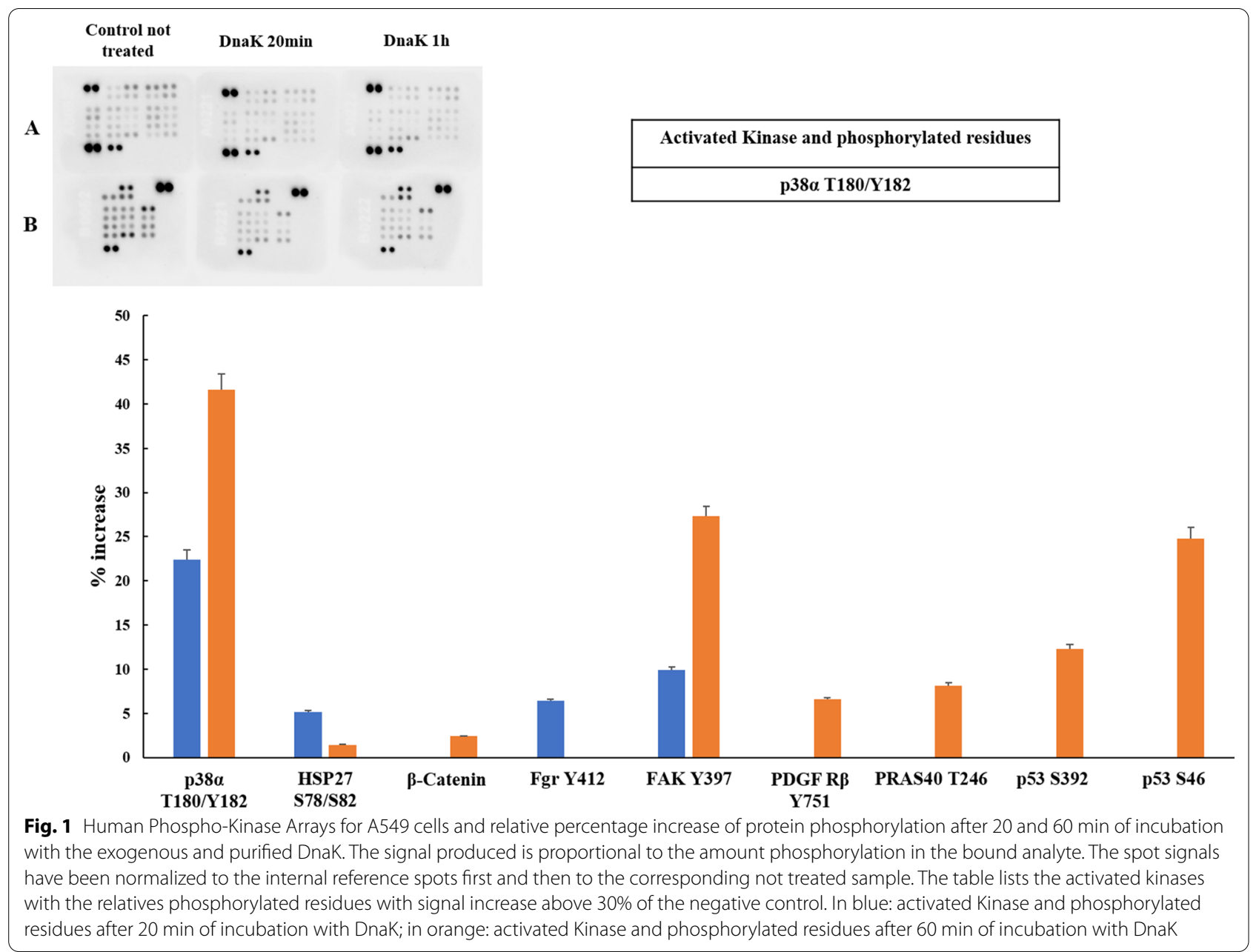

and p27). Two substrates were phosphorylated, namely HSP27 (above the threshold) and PRAS40 (just below threshold) (Fig. 2, Tables 1 and 2). HSP27 is a member of the small Hsp family, and it is one of the major players of many signaling pathways leading to carcinogenesis, resistance to anti-cancer-drug treatment, and apoptosis inhibition. Several studies report that HSP27 is overexpressed in many types of cancer and its functions are mainly regulated by phosphorylation [52]. PRAS40 is a substrate of Akt, with several effects on cell metabolism including cell survival and growth [53], and it has been implicated in different pathologic conditions, including cancer and insulin resistance [54-58].

\section{Effect of DnaK on PC-3 prostate cancer cell line}

The kinases activated above the threshold by DnaK in PC- 3 cell line were the Akt1/2/3 group and p70 S6 kinase of the AGC family, AMPK $\alpha 2$ of the CAMK family, and the ERK $1 / 2 / 3$ group of the CMGC family. A number of others were activated just below threshold (namely GSK- $3 \alpha / \beta$, AMPK $\alpha 1$, TOR, HSP27 and $\beta$-catenin. Three substrates were phosphorylated, namely STAT $5 \alpha$, p 53 in Ser 15 and HSP60 (Fig. 3, Tables 1 and 2). Once phosphorylated, STATs forms homo- or heterodimers that translocate to the nucleus and function as transcription factors. Dysregulation of STAT5 $\alpha$ has been observed in cellular invasion, angiogenesis and immune evasion, and inhibition of STAT $5 \alpha$ has been demonstrated to enhance the sensitivity to cisplatin and 5FU in vitro [59]. P53 is arguably the most important anti-cancer protein in that, upon DNA damage, controls the correct and synchronized execution of both cell cycle arrest and apoptosis to allow for proper DNA repair. Phosphorylation of one of the key residues, serine 15 , has been shown to coordinate polyphosphorylation of p53 [60], and stabilize the protein through disruption of MDM2 binding [61]. Phosphorylation of serine 15 also prevents p53 from being exported from the nucleus and stimulates p53 transcriptional activity through the increased association with p300 coactivator [62]. For this reason, dysregulation of p53 can have profound effect on a cell's fate. HSP60 is a mitochondrial chaperon protein involved in protein import 


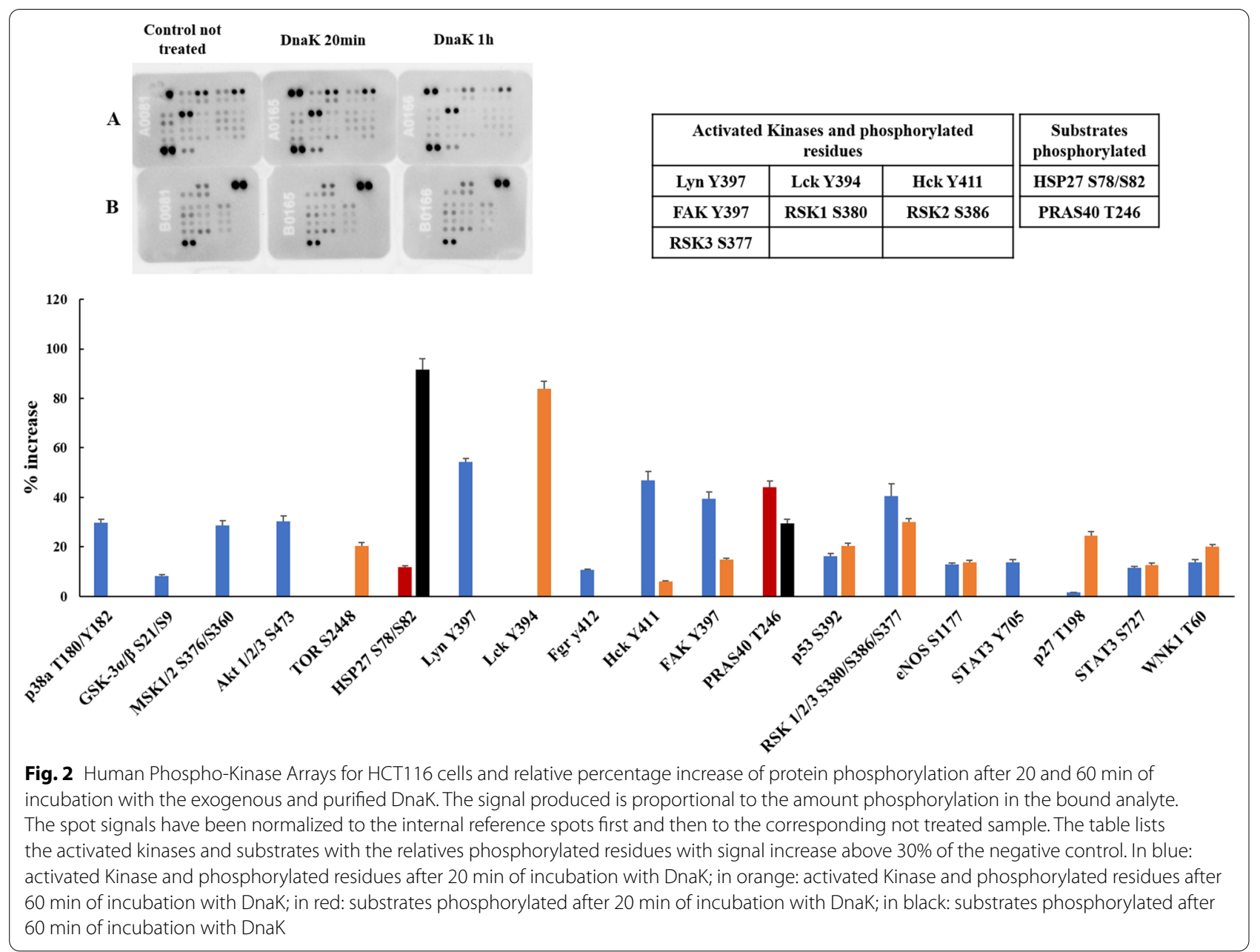

and assembly of macromolecules, which can also be present in the cytosol. Some studies have suggested that it has anti-apoptotic effect by inhibiting caspase- 3 activity $[63,64]$. Of note, the phosphorylation pattern of PC-3 cells was completely different that the one observed in HCT116.

\section{Effect of DnaK on SH-SY5Y neuroblastoma cell line}

A dynamic picture emerged by comparing $\mathrm{SH}-\mathrm{SY} 5 \mathrm{Y}$ cells differentiated and not differentiated. In fact, while they both showed widespread kinases phosphorylation, some kinases remained active through the differentiation phase while the activity of other decreased and new ones were activated in their place (compare, Fig. 4a, b and Table 1). More in detail, EGF R, Akt $1 / 2 / 3$ group, MSK $1 / 2$, ERK1/2/3 group and WNK1 were active in both differentiated and undifferentiated stages (Table 1). Fyn, FAK and TOR were active only in the not differentiated cells, with an additional number of kinases active just below the threshold level (JNK 1/2/3, AMK1 $\alpha 1$, Src, Lyn, STAT2, Fgr, p70 S6 kinase, p27) (Fig. 4a and Table 1). In the differentiated stage Lck, AMPK $\alpha 1 / 2$, JNK $1 / 2 / 3$ group and GSK- $3 \alpha / \beta$ were active above threshold, while CREB, STAT5 $\beta$, PYK2 were active slightly below threshold (Fig. $4 \mathrm{~b}$ and Table 1). Two substrates were phosphorylated in both stages (HSP27, c-Jun and p27) (Table 2), two were phosphorylated only in not differentiated cells (STAT3 and eNOS) (Fig. 4a and Table 2), and five more were phosphorylated in differentiated cells (STAT $5 \alpha$, STAT2, $\beta$-catenin, HSP60, PLC- $\gamma 1$ ) (Fig. 4b and Table 2). Phosphorylated HSP27 increases cell invasion, enhances cell proliferation and suppresses FAS-induced apoptosis in vitro [65]. Phosphorylated c-Jun dimerizes with c-Fos to form the transcription factor AP-1, and it is involved in cell cycle progression and apoptosis [66]. eNOS generates intracellular Nitric Oxide, which is involved in many cancer-related events [67]. p27 is an inhibitor of cyclin D dependent kinases, and is involved both in cell proliferation and differentiation [68]. PLC$\gamma 1$ (phospholipase gamma 1) is mostly involved in the 


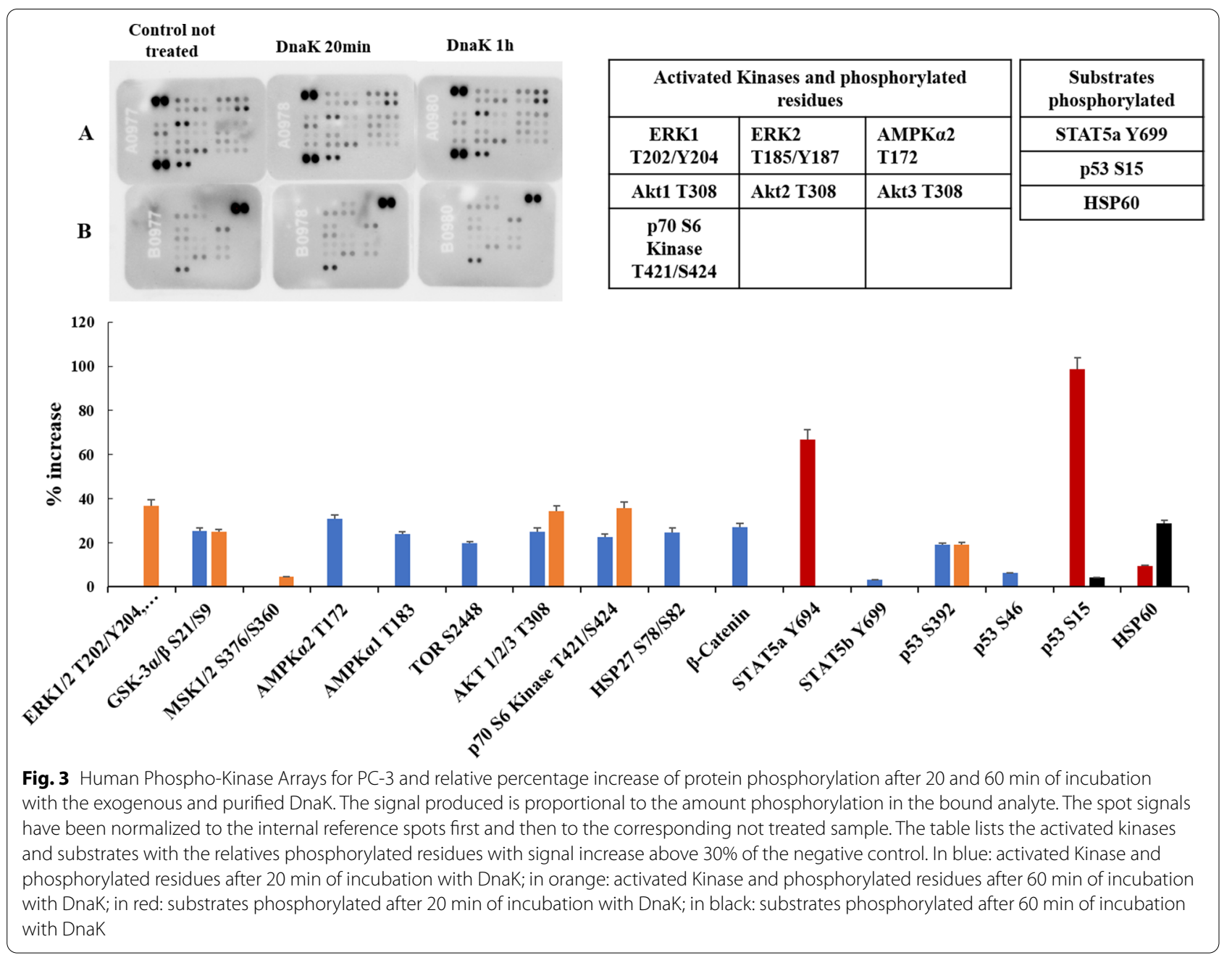

intracellular transduction of receptor-mediated tyrosine kinase signaling cascade [69]. STAT2 dysregulation may lead to activation of the pro-oncogenic STAT3 pathway [70]. These data are indeed better evaluated when the overlapping phosphorylated kinases and substrates in the different cancer cell lines were visualized using the Circos plot software (see "Materials and methods") (Fig. 5a, b). Overall, it seems that differentiation of SH-SY5Y is associated to a "switch" in the activation of certain kinases. In fact, FAK, Fyn and RSK $1 / 2 / 3$ change from phosphorylated in not differentiated cells, to non-phosphorylated in differentiated cells, while Lck, AMPK $\alpha 1 / 2$, GSK $3 \alpha / \beta$ and JNK $1 / 2 / 3$ change from not phosphorylated in not differentiated cells, to phosphorylated in differentiated cells (Table 1). In addition, we also observed a broadening of the number of phosphorylation substrates, with the inclusion of $\beta$-catenin, HSP60, PLC- $\gamma 1$, STAT2 and STAT5a in differentiated cells, while eNOS and STAT3 were not phosphorylated (Table 2 and Fig. 5a, b).

\section{Discussion}

Kinases play a prominent role in signal transduction and co-ordination of several complex cellular functions. In particular, their involvement in cellular proliferation and differentiation makes them important players and targets during the different steps of tumorigenesis [12]. We proposed Mycoplasma DnaK, a bacterial chaperone, as a potential link between the association of certain Mycoplasma with cancers and the molecular mechanisms involved in cellular transformation [39, 40]. Moreover, the ability of DnaK to be expressed on the bacterial surface and to bind other protein of the cellular membrane makes it a good candidate for further studies aimed at understanding its ability to influence tumor progression $[42,44,46,47]$. 


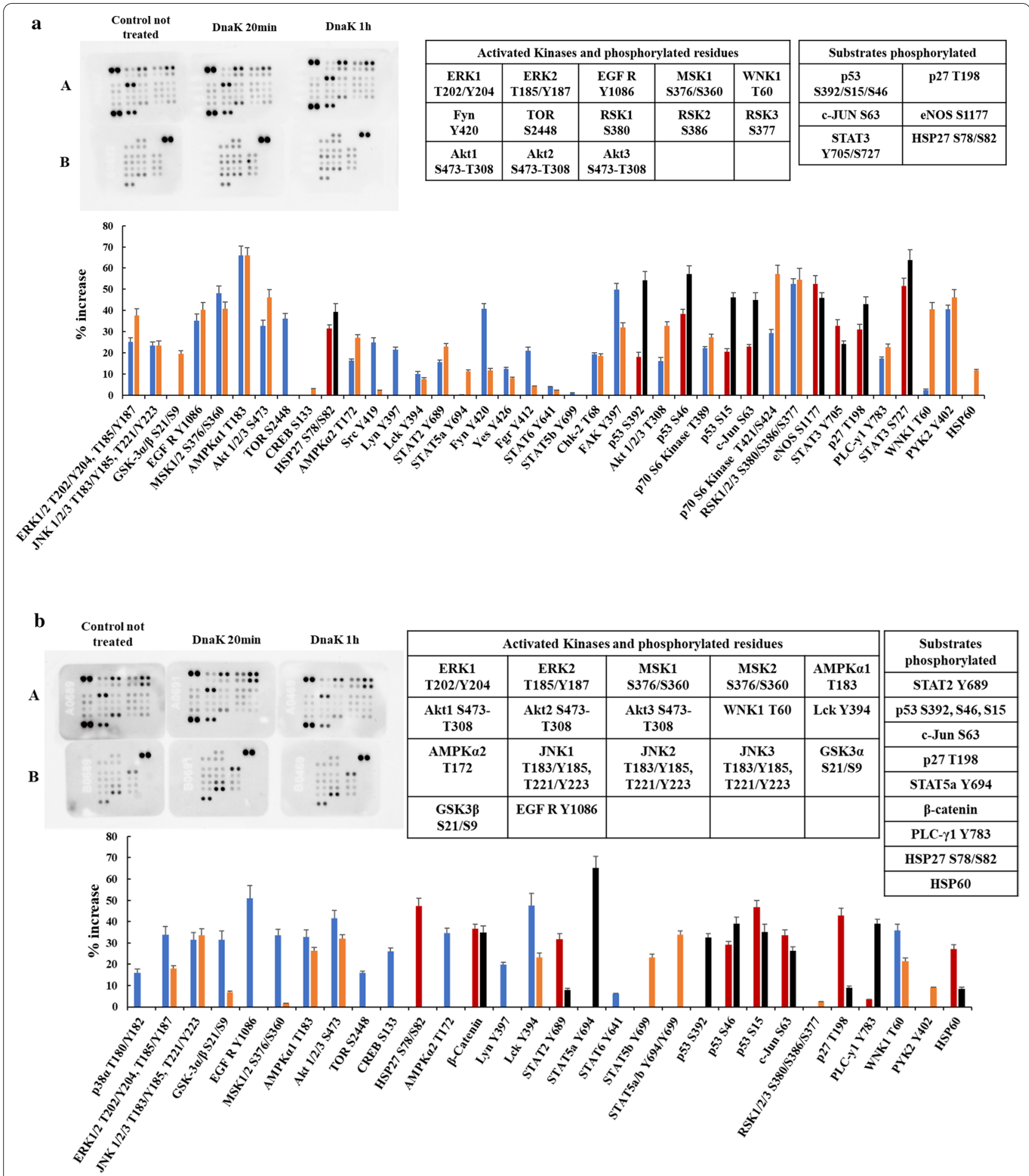

Fig. 4 Human Phospho-Kinase Arrays for SH-SY5Y not differentiated cells (a) and SH-SY5Y differentiated cells (b) and relative percentage increase of protein phosphorylation after 20 and 60 min of incubation with the exogenous and purified DnaK. The signal produced is proportional to the amount phosphorylation in the bound analyte. The spot signals have been normalized to the internal reference spots first and then to the corresponding not treated sample. The table lists the activated kinases and substrates with the relatives phosphorylated residues with signal increase above $30 \%$ of the negative control. In blue: activated Kinase and phosphorylated residues after 20 min of incubation with DnaK; in orange: activated Kinase and phosphorylated residues after 60 min of incubation with DnaK; in red: substrates phosphorylated after 20 min of incubation with DnaK; in black: substrates phosphorylated after 60 min of incubation with DnaK 
Table 1 List of phosphorylated kinases in cell lines treated with exogenous, purified DnaK

\begin{tabular}{|c|c|c|c|c|c|c|c|}
\hline \multirow[t]{2}{*}{ Phosphorylated kinase } & \multicolumn{5}{|c|}{ Cell line } & \multirow[t]{2}{*}{ Kinase family } & \multirow[t]{2}{*}{ Cancer association score } \\
\hline & A549 & НСT116 & PC3 & $\begin{array}{l}\text { SHSY5Y } \\
\text { not differentiated }\end{array}$ & $\begin{array}{l}\text { SHSY5Y } \\
\text { differentiated }\end{array}$ & & \\
\hline EGF RY1086 & & & & $x$ & $x$ & TK & 1 \\
\hline FAKY397 & & $x$ & & $x$ & & TK & 1 \\
\hline FgrY412 & & & & & & TK & 1 \\
\hline Fyn Y420 & & & & $x$ & & TK & 1 \\
\hline Hck Y411 & & $x$ & & & & TK & 1 \\
\hline Lyn Y397 & & $x$ & & & & TK & 1 \\
\hline Lck Y394 & & $x$ & & & $x$ & TK & 1 \\
\hline PDGF Rß Y751 & & & & & & TK & 1 \\
\hline PYK2 Y402 & & & & & & TK & 0.263 \\
\hline Src Y419 & & & & & & TK & 1 \\
\hline Yes Y426 & & & & & & TK & 1 \\
\hline Akt1/2/3 S473-T308 & & & $x$ & $x$ & $x$ & AGC & 1 \\
\hline MSK1/2 S376/S360 & & & & $x$ & $x$ & AGC & N/A \\
\hline p70 S6 Kinase T421/S424 & & & $x$ & & & AGC & 0.594 \\
\hline RSK1/2/3 S380/S386/S377 & & $x$ & & $x$ & & $A G C$ & $0.490 / 0.516 / 0.872$ \\
\hline AMPKa1T183 & & & & & $x$ & CAMK & 0.608 \\
\hline AMPKa2T172 & & & $x$ & & $x$ & CAMK & 0.983 \\
\hline Chk-2T68 & & & & & & CAMK & 1 \\
\hline ERK1/2/3 T202/Y204,T185/Y187 & & & $x$ & $x$ & $x$ & CMGC & $0.718 / 0.785$ \\
\hline GSK3a/ß S21/S9 & & & & & $x$ & CMGC & 1 \\
\hline JNK1/2/3 T183/Y185,T221/Y223 & & & & & $x$ & CMGC & $0.572 / 0.516 / 0.440$ \\
\hline p38aT180/Y182 & $x$ & & & & & CMGC & 0.291 \\
\hline WNK1 T60 & & & & $x$ & $x$ & STE & 0.283 \\
\hline TOR S2448 & & & & $x$ & & Atypical & N/A \\
\hline
\end{tabular}

Numbers represents phosphorylation sites

$S$ serine, $T$ threonine, $Y$ tyrosine, $x$ protein phosphorylated

Table 2 List of phosphorylated substrates in cell lines treated with exogenous, purified DnaK

\begin{tabular}{|c|c|c|c|c|}
\hline \multirow[t]{2}{*}{ Phosphorylated substrate } & \multicolumn{4}{|l|}{ Cell line } \\
\hline & НСТ116 & PC3 & SHSY5Y not differentiated & SHSY5Y differentiated \\
\hline$\beta$-Catenin & & & & $x$ \\
\hline \multicolumn{5}{|l|}{ CREB1 } \\
\hline HSP27 & S78/S82 & & S78, S82 & S78, S82 \\
\hline HSP60 & $x$ & & & x \\
\hline c-JUN & & & S63 & S63 \\
\hline eNOS & & & S1177 & \\
\hline p27 & & & T198 & T198 \\
\hline p53 & & S15 & S15, S46, S392 & S15, S46, S392 \\
\hline PLC- $\gamma 1$ & & & & Y783 \\
\hline PRAS40 & T246 & & & \\
\hline STAT2 & & & & Y689 \\
\hline STAT3 & & & Y705, S727 & \\
\hline STAT5a & & xY699 & & XY694 \\
\hline
\end{tabular}

Numbers represents phosphorylation sites

$S$ serine, $T$ threonine, $Y$ tyrosine, $P$ protein phosphorylated, unknown site 


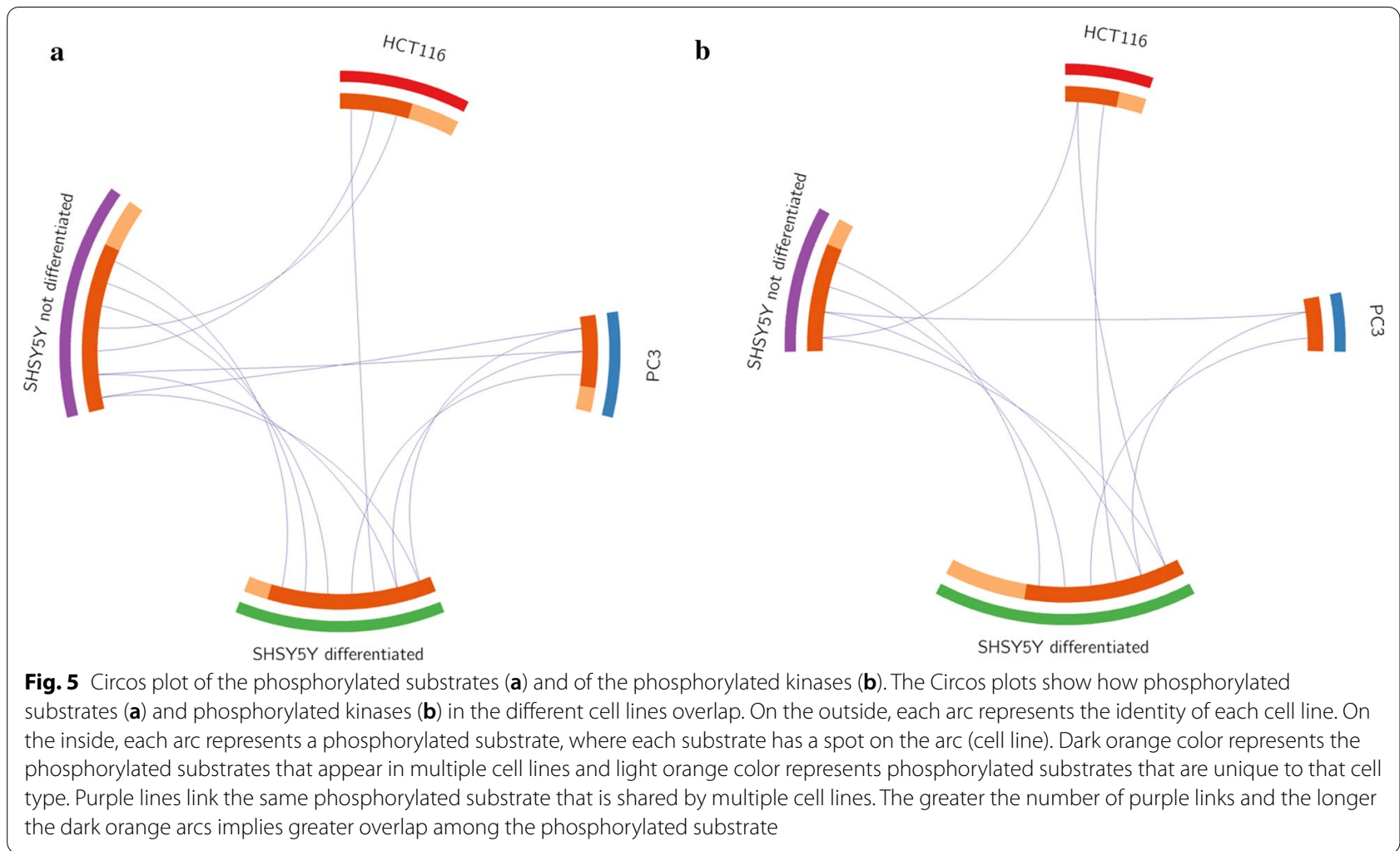

To our knowledge, this is the first time that an exogenous bacterial DnaK has been studied in the context of interaction with human receptor-mediated kinases present on different cancer cells and their subsequent activation. In this paper, we investigated the possibility that exogenous and purified DnaK added to cancer cell lines could activate specific kinases involved in carcinogenesis and cancer progression. Our experimental settings relied on an in vitro assay to measure kinase activation at different time point, and on the Kinome activity pathway analysis. We selected different cell lines representative of different cancer types, namely colon adenocarcinoma, lung and prostate cancer $[36,71]$. It is important to note that Mycoplasmas and their proteins are a component of the common tumor microenvironment surrounding all the three tissues [72]. The fourth cancer line, a neuroblastoma cell line, was selected because of the increasingly important association between gut and brain [73, 74], and the hypothesis that microbial proteins released by the gut microbiota (to which Mycoplasmas belongs) could influence brain functions and cancers [75].

Our data clearly show that exogenous DnaK is able to trigger activation of certain kinase-related transduction pathways in a cell-specific way. In particular, while lung carcinoma seems to be the least sensitive, a notable effect was seen on both undifferentiated neuroblastoma cells, and more so in the differentiated ones. The effect on colon carcinoma and prostate cancer cell lines was in the middle of the range observed in the neuroblastoma cells. The reason for this apparent cell-specific response is not clear. The most likely hypothesis is that differentiation either cause selective expression of certain cellular receptors on particular cancer cells, able to bind exogenous DnaK and transduce of kinase cascade [76-78]. In addition, differentiation could also increase expression of specific kinases, and indeed differentiated neuronal cells have increased expression of FAK, essential for cell adhesion and migration [79]. Kinases activation in turn caused the phosphorylation of specific substrates, which would indicate engagement of certain particular cell functions. Among the different kinases activated in our in vitro system, a substantial number are found strongly associate with certain cancers, as indicated by the association score. Indeed, most of the kinases phosphorylated in the presence of DnaK play a role in the DNA double strand response (both sensing and recruitment of other proteins for repair), cell cycle and apoptosis, metabolism, cell differentiation and proliferation.

It is important to note that the DnaK-mediated kinase activation profile of one cell line belonging to a particular cancer type may be cell-line specific and not necessarily reflect the DnaK-mediated kinase activation signature of 
this cancer type. The analysis of multiple cell lines of a particular cancer type would be needed to establish such a signature.

To better study the role of exogenous DnaK and expand our results by including additional cell types, it should be of interest to analyze DnaK-mediated kinase activation of micro-environmental cells that have well characterized roles in cancer progression such as Tumor-Associated Macrophages (TAMs) or Cancer-Associated Fibroblasts (CAFs). Additional experiments are also needed to characterize the effects that may result from the stimulation of these kinases on different cellular pathways and their outcome(s) on the cellular differentiation ability and functions. Finally, we point out that one limitation of our assay consists in the lack of properly address the response of other important kinases not included in the array, like for example the PKC family whose member are involved in regulating important cell functions [80, 81], and for this reason further experiments are also needed to better understand the potential relationship between DnaK and other potentially relevant kinases.

Based on our data, we hypothesize that the presence of exogenous DnaK in the tumor microenvironment may contribute to a status of cellular hyperactivation. In fact, even if our in vitro settings are very different from the situation in vivo, nonetheless the complex tumor microenvironment with its milieu of pro-inflammatory cytokines is most likely stimulating cancer cells to express a number of receptors, potentially providing additional binding targets for DnaK which then would trigger activation of specific kinases. In turn, this could result in dysregulated cellular pathways, including reduced repair activity, increased proliferation and reduced response to proapoptotic signals of certain tumors (or tumor stages). Our data identify a potential role of Mycoplasma DnaK for cancer progression, and given the similarity in structure and aminoacid composition of this protein with other bacterial DnaKs, such as H. pylori and F. nucleatum [39] we provide a novel mechanism whereby components of the human microbiota are able to promote carcinogenesis and cancer progression once released in the tumor microenvironment [82]. Additional experiments are ongoing to identify the receptors able to bind to DnaK and transduce the signals.

\section{Conclusions}

Our results point to a new role for Mycoplasma DnaK, and by extension other bacterial DnaKs with similar structure and aminoacidic compositions, present in the tumor microenvironment, in upregulating the phosphorylation activity of certain kinases involved in carcinogenesis and cancer progression. Our data could be relevant in determining a new role for this bacterial chaperon protein thus potentially establishing a new target for anti-cancer therapy aimed at reducing cancer progression.

\begin{abstract}
Abbreviations
p38a: P38 mitogen-activated protein kinases; ERK1/2: Extracellular signalregulated kinases; JNK 1/2/3: C-Jun N-terminal kinases; Hck: Hematopoietic cell kinase; Lyn: Lck/Yes novel tyrosine kinase; Lck: Lymphocyte-specific protein tyrosine kinase; RSK1/2/3: $90 \mathrm{KDa}$ ribosomal S6 kinase; MSK1/2: Mitogen and stress activated protein kinase; Akt1/2/3: Protein kinase B; p27: Cyclin-dependent kinase inhibitor 1B; HSP27: Heat shock protein 27: PRAS40: Proline-rich Akt substrate of 40 kDa; FAK: Focal Adhesion Kinase; GSK-3a/ $\beta$ : Glycogen synthase kinase 3; AMPK: AMP-activated protein kinase; TOR: Target of rapamycin; WNK1: Lysine deficient protein kinase 1; Fgr: Gardner-Rasheed feline sarcoma viral ( $v$-fgr) oncogene homolog; EGF R: Epidermal growth factor receptor; CREB: CAMP response element-binding protein; Src: Proto-oncogene tyrosine-protein kinase Src; Fyn: Proto-oncogene tyrosine-protein kinase Fyn; Yes: Proto-oncogene tyrosine-protein kinase Yes; Chk-2: Checkpoint kinase 2; PLC- 1 1: Phosphoinositide phospholipase C isoform $\gamma$; PYK2: Proline-rich tyrosine kinase 2; HSP60: Heat shock protein 60; PDGF RB: Platelet-derived growth factor receptor beta; p53: Tumor protein p53; eNOS: Endothelial NOS also known as nitric oxide synthase 3; STAT: Signal transducer and activator of transcription protein family.
\end{abstract}

\section{Acknowledgements}

Not applicable.

\section{Authors' contributions}

FB designed research, performed research, analyzed data and wrote the paper; SC analyzed data and wrote the paper, RCG designed research and wrote the paper, and DZ designed research and wrote the paper. All authors read and approved the final manuscript.

\section{Funding}

This work was supported by internal funds of the Institute of Human Virology, School of Medicine, University of Maryland, Baltimore, USA.

\section{Availability of data and materials}

All data utilized, generated or analyzed during these studies are included in this published article.

\section{Ethics approval and consent to participate}

Not applicable.

\section{Consent for publication}

All authors consent for publication.

\section{Competing interests}

The authors declare that they have no competing interests.

\section{Author details}

${ }_{1}^{1}$ Institute of Human Virology and Global Virus Network Center, Department of Biochemistry and Molecular Biology, University of Maryland School of Medicine, Baltimore, MD 21201, USA. ${ }^{2}$ Institute of Human Virology and Global Virus Network Center, Department of Medicine, University of Maryland School of Medicine, Baltimore, MD 21201, USA.

Received: 6 January 2021 Accepted: 1 February 2021

Published online: 09 February 2021

\section{References}

1. Roskoski R Jr. A historical overview of protein kinases and their targeted small molecule inhibitors. Pharmacol Res. 2015;100:1-23.

2. Manning $\mathrm{G}$, et al. The protein kinase complement of the human genome. Science. 2002;298(5600):1912-34. 
3. Venter JC, et al. The sequence of the human genome. Science. 2001;291(5507):1304-51.

4. Leroux AE, Schulze JO, Biondi RM. AGC kinases, mechanisms of regulation and innovative drug development. Semin Cancer Biol. 2018:48:1-17.

5. Takemoto-Kimura S, et al. Calmodulin kinases: essential regulators in health and disease. J Neurochem. 2017;141(6):808-18.

6. Cozza G, Pinna LA. Casein kinases as potential therapeutic targets. Expert Opin Ther Targets. 2016;20(3):319-40.

7. Varjosalo M, et al. The protein interaction landscape of the human CMGC kinase group. Cell Rep. 2013;3(4):1306-20.

8. Miller CJ, et al. Comprehensive profiling of the STE20 kinase family defines features essential for selective substrate targeting and signaling output. PLoS Biol. 2019;17(3):e2006540.

9. Duong-Ly KC, Peterson JR. Chapter 2: The human kinome and kinase inhibition. In: Current protocols in pharmacology. New York: Wiley; 2013. p. Unit2.9.

10. Jiao $Q$, et al. Advances in studies of tyrosine kinase inhibitors and their acquired resistance. Mol Cancer. 2018;17(1):36.

11. Kanev GK, et al. The landscape of atypical and eukaryotic protein kinases. Trends Pharmacol Sci. 2019:40(11):818-32.

12. Bhullar KS, et al. Kinase-targeted cancer therapies: progress, challenges and future directions. Mol Cancer. 2018;17(1):48.

13. Zhao Y, Wang X. PLK4: a promising target for cancer therapy. J Cancer Res Clin Oncol. 2019;145(10):2413-22.

14. Pópulo H, Lopes JM, Soares P. The mTOR signalling pathway in human cancer. Int J Mol Sci. 2012;13(2):1886-918.

15. Lee BY, et al. FAK signaling in human cancer as a target for therapeutics. Pharmacol Ther. 2015;146:132-49.

16. Roskoski R Jr. Targeting ERK1/2 protein-serine/threonine kinases in human cancers. Pharmacol Res. 2019;142:151-68.

17. Kittler $\mathrm{H}$, Tschandl P. Driver mutations in the mitogen-activated protein kinase pathway: the seeds of good and evil. Br J Dermatol. 2018;178(1):26-7.

18. Maurer G, Tarkowski B, Baccarini M. Raf kinases in cancer-roles and therapeutic opportunities. Oncogene. 2011;30(32):3477-88.

19. Pillai $P$, et al. Cancer kinases and its novel inhibitors: past, present and future challenges. Curr Drug Targets. 2015;16(11):1233-45.

20. Zangouei AS, et al. Role of tyrosine kinases in bladder cancer progression: an overview. Cell Commun Signal. 2020;18(1):127.

21. Saylor PJ, Escudier B, Michaelson MD. Importance of fibroblast growth factor receptor in neovascularization and tumor escape from antiangiogenic therapy. Clin Genitourin Cancer. 2012;10(2):77-83.

22. Asakawa $\mathrm{H}$, et al. Chemosensitivity of anaplastic thyroid carcinoma and poorly differentiated thyroid carcinoma. Anticancer Res. 1997;17(4a):2757-62.

23. Sugawara l, et al. Expression of multidrug resistance-associated protein (MRP) in thyroid cancers. Cancer Lett. 1995;95(1):135-8.

24. Wang $\mathrm{SH}$, et al. Susceptibility of thyroid cancer cells to 7-hydroxystaurosporine-induced apoptosis correlates with $\mathrm{BCl}-2$ protein level. Thyroid. 2001;11(8):725-31.

25. Kawahito Y, et al. Mycoplasma fermentans glycolipid-antigen as a pathogen of rheumatoid arthritis. Biochem Biophys Res Commun. 2008:369(2):561-6.

26. Gilroy CB, Keat A, Taylor-Robinson D. The prevalence of Mycoplasma fermentans in patients with inflammatory arthritides. Rheumatology. 2001;40(12):1355-8

27. Yanez A, et al. Animal model of Mycoplasma fermentans respiratory infection. BMC Res Notes. 2013;6:9.

28. Taylor-Robinson D, Furr PM. Models of infection due to mycoplasmas, including Mycoplasma fermentans, in the genital tract and other sites in mice. Clin Infect Dis. 1993;17(Suppl 1):S280-2.

29. Tully JG, et al. A newly discovered mycoplasma in the human urogenital tract. Lancet. 1981;1(8233):1288-91.

30. D'Alonzo R, et al. Pathogenesis and treatment of neurologic diseases associated with Mycoplasma pneumoniae infection. Front Microbiol. 2018:9:2751.

31. Vogtmann E, Goedert JJ. Epidemiologic studies of the human microbiome and cancer. Br J Cancer. 2016;114(3):237-42.

32. Reddel RR, et al. Development of tumorigenicity in simian virus 40-immortalized human bronchial epithelial cell lines. Cancer Res. 1993:53(5):985-91.
33. Choi HS, et al. Detection of mycoplasma infection in circulating tumor cells in patients with hepatocellular carcinoma. Biochem Biophys Res Commun. 2014:446(2):620-5.

34. Patil S, Rao RS, Raj AT. Role of Mycoplasma in the initiation and progression of oral cancer. J Int Oral Health. 2015;7(7):i-ii.

35. Namiki K, et al. Persistent exposure to Mycoplasma induces malignant transformation of human prostate cells. PLoS ONE. 2009;4(9):e6872.

36. Barykova YA, et al. Association of Mycoplasma hominis infection with prostate cancer. Oncotarget. 2011;2(4):289-97.

37. Zhang S, et al. Mycoplasma fermentans infection promotes immortalization of human peripheral blood mononuclear cells in culture. Blood. 2004;104(13):4252-9.

38. Zhang S, Tsai S, Lo S-C. Alteration of gene expression profiles during mycoplasma-induced malignant cell transformation. BMC Cancer. 2006;6:116-116.

39. Zella D, et al. Mycoplasma promotes malignant transformation in vivo, and its DnaK, a bacterial chaperone protein, has broad oncogenic properties. Proc Natl Acad Sci. 2018:115(51):E12005-14.

40. Benedetti F, et al. Role of Mycoplasma chaperone DnaK in cellular transformation. Int J Mol Sci. 2020;21(4):1311.

41. Kim MK, et al. Mycoplasma infection promotes tumor progression via interaction of the mycoplasmal protein p37 and epithelial cell adhesion molecule in hepatocellular carcinoma. Cancer Lett. 2019;454:44-52.

42. Bendtsen JD, et al. Non-classical protein secretion in bacteria. BMC Microbiol. 2005;5(1):58.

43. Carrio MM, Villaverde A. Localization of chaperones DnaK and GroEL in bacterial inclusion bodies. J Bacteriol. 2005:187(10):3599-601.

44. Hagemann L, et al. The surface-displayed chaperones GroEL and DnaK of Mycoplasma pneumoniae interact with human plasminogen and components of the extracellular matrix. Pathog Dis. 2017;75(3):ftx017.

45. Mambula SS, et al. Mechanisms for Hsp70 secretion: crossing membranes without a leader. Methods. 2007;43(3):168-75.

46. Henderson B, Martin A. Bacterial virulence in the moonlight: multitasking bacterial moonlighting proteins are virulence determinants in infectious disease. Infect Immun. 2011;79(9):3476-91.

47. Henderson B. An overview of protein moonlighting in bacterial infection. Biochem Soc Trans. 2014;42(6):1720-7.

48. Lopes FM, et al. Comparison between proliferative and neuron-like SHSY5Y cells as an in vitro model for Parkinson disease studies. Brain Res. 2010;1337:85-94.

49. Eid S, et al. KinMap: a web-based tool for interactive navigation through human kinome data. BMC Bioinform. 2017:18(1):16.

50. Yang J, et al. Targeting PI3K in cancer: mechanisms and advances in clinical trials. Mol Cancer. 2019;18(1):26.

51. Oda K, et al. p53AIP1, a potential mediator of p53-dependent apoptosis, and its regulation by Ser-46-phosphorylated p53. Cell. 2000;102(6):849-62.

52. Katsogiannou M, Andrieu C, Rocchi P. Heat shock protein 27 phosphorylation state is associated with cancer progression. Front Genet. 2014;5:346-346.

53. Kazi AA, Lang CH. PRAS40 regulates protein synthesis and cell cycle in C2C12 myoblasts. Mol Med. 2010;16(9):359-71.

54. Nascimento EBM, et al. Insulin-mediated phosphorylation of the prolinerich Akt substrate PRAS40 is impaired in insulin target tissues of high-fat diet-fed rats. Diabetes. 2006:55(12):3221.

55. Wiza C, et al. Over-expression of PRAS40 enhances insulin sensitivity in skeletal muscle. Arch Physiol Biochem. 2014;120(2):64-72.

56. Wanyeon $\mathrm{K}$, et al. PIM1-activated PRAS40 regulates radioresistance in non-small cell lung cancer cells through interplay with FOXO3a, 14-3-3 and protein phosphatases. Radiat Res. 2011;176(5):539-52.

57. Huang $L$, et al. PRAS40 is a functionally critical target for EWS repression in Ewing sarcoma. Can Res. 2012;72(5):1260.

58. Yuan K, et al. Phospho-PRAS40Thr246 predicts trastuzumab response in patients with HER2-positive metastatic breast cancer. Oncol Lett. 2015;9(2):785-9.

59. Hong $X$, et al. STAT5a-targeting miRNA enhances chemosensitivity to cisplatin and 5-fluorouracil in human colorectal cancer cells. Mol Med Rep. 2012;5(5):1215-9.

60. Kapoor M, et al. Cooperative phosphorylation at multiple sites is required to activate p53 in response to UV radiation. Oncogene. 2000;19(3):358-64. 
61. Shieh SY, et al. DNA damage-induced phosphorylation of p53 alleviates inhibition by MDM2. Cell. 1997;91(3):325-34.

62. Zhang Y, Xiong Y. A p53 amino-terminal nuclear export signal inhibited by DNA damage-induced phosphorylation. Science. 2001;292(5523):1910-5.

63. Chandra D, Choy G, Tang DG. Cytosolic accumulation of HSP60 during apoptosis with or without apparent mitochondrial release: evidence that its pro-apoptotic or pro-survival functions involve differential interactions with caspase-3. J Biol Chem. 2007;282(43):31289-301.

64. Campanella C, et al. Upon oxidative stress, the antiapoptotic Hsp60/ procaspase-3 complex persists in mucoepidermoid carcinoma cells. Eur J Histochem. 2008;52(4):221-8.

65. Voll EA, et al. Heat shock protein 27 regulates human prostate cancer cell motility and metastatic progression. Oncotarget. 2014;5(9):2648-63.

66. Wisdom R, Johnson RS, Moore C. c-Jun regulates cell cycle progression and apoptosis by distinct mechanisms. EMBO J. 1999;18(1):188-97.

67. Connelly $L$, et al. Biphasic regulation of NF-kappa B activity underlies the pro- and anti-inflammatory actions of nitric oxide. J Immunol. 2001;166(6):3873-81.

68. Chu IM, Hengst L, Slingerland JM. The Cdk inhibitor p27 in human cancer: prognostic potential and relevance to anticancer therapy. Nat Rev Cancer. 2008;8(4):253-67.

69. Kadamur G, Ross EM. Mammalian phospholipase C. Annu Rev Physiol. 2013;75(1):127-54.

70. Gamero AM, et al. STAT2 contributes to promotion of colorectal and skin carcinogenesis. Cancer Prev Res. 2010;3(4):495-504

71. Huang $S$, et al. Mycoplasma infections and different human carcinomas. World J Gastroenterol. 2001;7(2):266-9.

72. Benedetti F, Curreli S, Zella D. Mycoplasmas-host interaction: mechanisms of inflammation and association with cellular transformation. Microorganisms. 2020;8(9):1351.
73. Cryan JF, et al. The microbiota-gut-brain axis. Physiol Rev. 2019;99(4):1877-2013.

74. Muller PA, et al. Microbiota modulate sympathetic neurons via a gut-brain circuit. Nature. 2020;583(7816):441-6.

75. Mehrian-Shai $\mathrm{R}$, et al. The gut-brain axis, paving the way to brain cancer Trends Cancer. 2019;5(4):200-7.

76. Shipley MM, Mangold CA, Szpara ML. Differentiation of the SH-SY5Y human neuroblastoma cell line. J Vis Exp. 2016;108:53193.

77. Teppola H, et al. Morphological differentiation towards neuronal phenotype of SH-SY5Y neuroblastoma cells by estradiol, retinoic acid and cholesterol. Neurochem Res. 2016;41(4):731-47.

78. Korecka JA, et al. Phenotypic characterization of retinoic acid differentiated SH-SY5Y cells by transcriptional profiling. PLOS ONE. 2013;8(5):e63862-e63862.

79. Dwane S, Durack E, Kiely PA. Optimising parameters for the differentiation of SH-SY5Y cells to study cell adhesion and cell migration. BMC Res Notes. 2013;6:366-366.

80. Martini S, et al. PKC $\varepsilon$ controls mitotic progression by regulating centrosome migration and mitotic spindle assembly. Mol Cancer Res. 2018;16(1):3-15.

81. Isakov N. Protein kinase C (PKC) isoforms in cancer, tumor promotion and tumor suppression. Semin Cancer Biol. 2018;48:36-52.

82. Maman S, Witz IP. A history of exploring cancer in context. Nat Rev Cancer. 2018;18(6):359-76.

\section{Publisher's Note}

Springer Nature remains neutral with regard to jurisdictional claims in published maps and institutional affiliations.
Ready to submit your research? Choose BMC and benefit from:

- fast, convenient online submission

- thorough peer review by experienced researchers in your field

- rapid publication on acceptance

- support for research data, including large and complex data types

- gold Open Access which fosters wider collaboration and increased citations

- maximum visibility for your research: over 100M website views per year

At BMC, research is always in progress.

Learn more biomedcentral.com/submissions 